\title{
RELAÇÕES ETNICO-RACIAS: O PENSAMENTO DECOLONIAL E A PRÁtICA PEDAGÓGICA PARA UMA EDUCAÇÃO ANTIRRACISTA
}

\author{
Daniele da Silva Costa ${ }^{1}$ \\ Rayane Corrêa Pantoja ${ }^{2}$ \\ Waldir Ferreira de $\mathrm{Abreu}^{3}$
}

\section{RESUMO}

O objetivo deste texto é refletir sobre as relações etnico-raciais a partir do pensamento e prática pedagógica decolonizadora no enfrentamento do racismo. Tomamos como questões de pesquisa algumas inquietações: De que forma o negro (a) é representado historicamente no contexto brasileiro? Como as discussões contra o racismo estão presentes no campo educacional? Em que amplitude as questões de racismo e do antirracismo no âmbito da história da educação no Brasil caminham para o pensamento decolonial? A metodologia adotada para esta discussão, volta-se a revisão bibliográfica e análise documental em Análise de Conteúdo (AC) proposto por Bardin $(2006,2011)$. Uma das conclusões que este estudo levantou é o apontamento da necessidade de reflexões conjuntas para a prática pedagógica decolonial e a partir disto os efeitos que o racismo provoca na identidade étnico-racial dos sujeitos sociais presentes na escola possam ser colocados em prática para uma educação antirracista.

\footnotetext{
1 Mestre em educação e Cultura pela UFPA; Professora na Prefeitura de Moju e Professora Substituta IFPA-Abaetetuba, integrante do Grupo de Estudos e Pesquisas em Educação, Infância e Filosofia - GEPEIF/UFPA/CNPq. E-mail: dsc2709@yahoo.com.br/ daniele.costa@ifpa.edu.br

2 Licenciada Plena em Pedagogia pela Universidade do Estado do Pará. E-mail: rayane.crr19@gmail.com.

3 Doutor em Ciências Humanas e Educação pela PUC/RIO, Professor Adjunto II da Universidade Federal do Pará, líder do Grupo de Estudos e Pesquisas em Educação, Infância e Filosofia - GEPEIF/UFPA/CNPq. E-mail: awaldir@ufpa.br.
} 
Palavras-chave: Educação antirracista. Prática pedagógica. Decolonial.

\section{ETHNIC-RACIAL RELATIONSHIPS: DECOLONIAL THOUGHT AND PEDAGOGICAL PRACTICE FOR ANTI-RACIST EDUCATION}

\section{ABSTRACT}

The purpose of this text is to reflect on ethnic-racial relations based on decolonizing pedagogical thinking and practice in the fight against racism. We take as concerns research questions some concerns: How is the black person (a) historically represented in the Brazilian context? How are discussions against racism present in the educational field? To what extent do the issues of racism and antiracism within the scope of the history of education in Brazil move towards decolonial thinking? The methodology adopted for this discussion, turns to bibliographic review and document analysis in Content Analysis (CA) proposed by Bardin $(2006,2011)$. One of the conclusions raised by this study is the need for joint reflections for decolonial pedagogical practice and from this the effects that racism causes on the ethnic-racial identity of social subjects present at school can be put into practice for an anti-racist education.

Keywords: Anti-racist education. Pedagogical practice. Decolonial.

RELACIONES

DESCOLONIAL EDUCACIÓN ANTIRRACISTA

ETNICO-RACIALES:

PENSAMIENTO

\section{RESUMEN}

El objetivo de este trabajo es reflexionar sobre las relaciones étnicoraciales desde el pensamiento y la práctica pedagógica decolonizadora en la lucha contra el racismo. Tomar como preguntas de investigación algunas preocupaciones: ¿En qué forma el negro (A) está representado históricamente en el contexto brasileño? Como los 
debates contra el racismo están presentes en el campo educativo? A medida que los problemas de racismo y de antirracismo dentro de la historia de la educación en Brasil ir al pensamiento descolonial? La metodología adoptada para la discusión, se remonta a la revisión de la literatura y el análisis documental en análisis de contenido (AC) propuesto por Bardin $(2006,2011)$. Una de las conclusiones que de este estudio se ha planteado es la Accommodator la necesidad de reflexión conjunta para la práctica pedagógica y decolonial desde este racismo los efectos que provoca en la identidad étnica racial- de los sujetos sociales presentes en la escuela se pueden poner en práctica para una educación antirracista.

Palabras clave: Educación anti-raista. Práctica pedagógica. Decolonial.

\section{INTRODUÇÃO}

No decorrer da história brasileira, passamos por uma política de embranquecimento, o governo da república fomentou a imigração de outros povos europeus, "convidados" a adentrar em nosso país, sob o pretexto de trabalharem e aqui criar raízes, bem como melhorar a "raça degenerada" da qual nascemos, a saber, a negra. Por conseguinte, com a diluição da nossa cor, todo o tipo de violência sofrida pelos nossos ancestrais desumanizados pela escravidão e pelo padrão Europeu supervalorizado, temos vergonha do ser negra (o), ou mesmo, ser afrodescendente. E essa é uma questão dolorosa demais para o nosso consciente lidar e, talvez por isso, permaneça escondido em nosso inconsciente surgindo apenas quando somos questionados sobre a nossa cor/raça, pois o censo do Instituto Brasileiro de Geografia e Estatistica (IBGE) é medido conforme a nossa autodeclaração racial.

Para este estudo, adotou-se como objetivo: refletir sobre as relações etnico-raciais a partir do pensamento e prática pedagógica decolonizadora no enfrentamento do racismo. Tomamos como questões de pesquisa algumas inquietações: De que forma o negro (a) é representado historicamente no contexto brasileiro? Como as discussões contra o racismo estão presentes no campo educacional? 
Em que amplitude as questões de racismo e do antirracismo no âmbito da história da educação no Brasil caminham para o pensamento decolonial? Estas e outras inquietações se farão presentes neste estudo, para que o a a partir do pensamento social brasileiro face à questão racial bem como às trajetórias do Movimento Negro e das lutas contra o racismo no Brasil se institucionalizaram. Nesse preambulo, foi tecido um breve histórico do Movimento Negro no Brasil em que segundo Gomes (2017, p. 2127) desde seu surgimento este movimento social atua como um ator político reeducando a si mesmo e aos outros. Em sequência, os estudos decoloniais e por último a prática de uma Pedagogia Decolonial que permita aos educadores reflexões críticas frente a abordagem das discussões étnico-racial.

Contudo, é de fundamental importância tratar sobre a identidade étnico-racial, uma vez que quando falamos sobre a cultura negra estamos nos referindo a nossa cultura. Apesar de muitos tentarem apagá-la, a presença negra permanece em nós. Somos, herança de um passado escravocrata e escravagista não tão distante, e por isso é urgente que as (os) alunas (os) se reconheçam quanto seres políticos pertencentes a uma comunidade, uma vez que, essa ação poderá promover a autoestima, a valorização dos valores culturais e, por fim, a organização política da população negra no Brasil.

\section{CAMINHOS METODOLÓGICOS}

Utilizou-se nesta pesquisa, os procedimentos de revisão bibliográfica e análise documental em Análise de Conteúdo (AC) proposto por Bardin (2011), em que a autora ao definir este método analítico e sistemático, auxilia na organização e padronização dos dados coletados, análise do texto e seu significado. A importância do método da AC é de suma importância aos estudos atuais, devido a evolução constante de estudos científicos e principalmente a preocupação quanto ao rigor cientifico, possibilitando assim a produção legítima das ciências humanas.

Bardin (2006) define a análise de conteúdo como um conjunto de técnicas de analises e utiliza como procedimentos sistemático cuja 
intenção versa sobre a interferência e inferências de conhecimentos, cujo principal objetivo é ultrapassar as incertezas e enriquecer a leitura de dados coletados. Para isto, é importante considerar as etapas da $\mathrm{AC}$, sendo estas a pre-análise, fase de organização do material a ser analisado, sistematizando e organizando as ideias iniciais; em seguida a escolha de documentos, após a sistematização esta etapa toma para si a demarcação do que será analisado posteriormente; a terceira etapa a formulação das hipóteses e dos objetivos e por último, a referenciação dos índices e elaboração de indicadores, que envolve a determinação de indicadores por meio de recortes de texto nos documentos de análise.

Para isto, consideramos a constituição do corpus de dados da pesquisa utilizando como a fase inicial da AC o levantamento de materiais inseridos em fontes de informações tais como: livros, artigos e documentos, e por conseguinte a segunda fase delimitada a seleção de documentos, estes que compõe a temática abordada definida nos seguintes descritores de análise: decolonialidade, relações étnico-raciais e prática pedagógica. Diante disto foram selecionados no tratamento da categoria Decolonialidade obras delimitadas aos seguintes autores: Quijano (2000, 2005, 2007), Grosfoguel (2007, 2010), Walsh (2006, 2007, 2014), Mignolo (2003, 2005), Castro-Gómez (2005), Maldonado-Torres (2007), Fanon (2008), Oliveira (2018) e Ballestrin (2013). Em se tratando do segundo descritor relações étnico-raciais utlizou-se como referenciais: Guimarães (1999, 2003), Munanga (2001, 2004, 2009, 2017), Miranda (2010) e Gomes (2017). Por último, a categoria analisada nesta pesquisa discute a prática pedagógica, baseada nos estudos de: Freire (1987, 2009), Savianni (2005), Oliveira e Candau (2010), Arroyo (2012) e os PCN's(1997/1998). Por ultimo, consideramos a última fase da AC, a qual a partir do objetivo e das hipóteses anteriormente sinalisadas, possa-se construir caminhos de discussões cientificas em sua concretude.

\section{O MOVIMENTO NEGRO NO BRASIL}

A história de luta e do protagonismo do Movimento Negro na construção de políticas de equidade racial, visando o combate e 
superação do racismo, sendo este racismo diferente dos outros tipos de racismo manifestado em outras sociedades, pois o nosso país padece de um racismo ambíguo que se afirma por meio de uma negação Munanga (2017). Neste preâmbulo, é indispensável traçarmos a linha histórica destas lutas no Brasil, em que ao conceituarmos o racismo institucional - ou sistêmico - como um dos mecanismos estruturais que promove e legitima a exclusão específica dos grupos racialmente subordinados, como homens e mulheres negros, latinos e indígenas; induzidos, condicionados a organização e a ação do Estado. Sendo assim, ao estabelecer a definição do que seria o Movimento Negro, adotamos o conceito de Gomes (2017) como ponto de partida para esta discussão, definido como:

\begin{abstract}
[...] as mais diversas formas de organização e articulação das negras e dos negros politicamente posicionados na luta contra o racismo e que visam à superação desse perverso fenômeno na sociedade. [...] Trata-se de um movimento que não se reporta de forma romântica à relação entre os negros brasileiros, à ancestralidade africana e ao continente africano da atualidade, mas reconhece os vínculos históricos, políticos e culturais dessa relação, compreendendo-a como integrante da complexa diáspora africana. Portanto não basta apenas valorizar a presença e participação dos negros na história, na cultura e louvar a ancestralidade negra e africana para que um coletivo seja considerado como Movimento Negro. (p. 23-24)
\end{abstract}

Neste sentido, a partir da definição da autora, o Movimento Negro possui uma heterogeneidade em suas definições, todavia, entende-se que este movimento social dá-se pelas mais diversas formas de organização e articulação das negras e dos negros que se posicionam politicamente na luta contra o racismo.

O Movimento Negro no Brasil, não possui sede fixa, as entidades, as organizações e as pessoas que o compõem discutem a relação entre as pessoas negras, a ancestralidade e o continente Africano com criticidade e não reduzida a visões romantizadas de harmonia, como nos faz pensar o mito da democracia racial, que 
ganhou forte aceitação nos anos 30 através do livro Casa-Grande \& Senzala (FREYRE, 1933). Pois, para se considerar um Movimento Negro de fato, o coletivo deve posicionar-se explícita e politicamente frente ao racismo, aqui definido como um sistema de opressão que legitima a exclusão específica de segmentos sociais racialmente subordinados, como é o caso da população negra, considerada pela Pesquisa Nacional por Amostra de Domicílios (PNAD) do IBGE, em que 209,2 milhões de habitantes do território brasileiro, 19,2 milhões se consideram como pretos, enquanto 89,7 milhões de declaram na pesquisa como pardos, totalizando assim a soma de pretos e pardos $56,10 \%$ da população negra no Brasil, dados que se configuram como a representatividade do nosso povo que tem seus direitos negados diariamente, seja ele na educação, saúde, assistência, mas fortalecido nos movimentos populares espalhados pelo brasil, na luta pela garantia de direitos essenciais.

Historicamente, a luta da população negra data desde a resistência de diversas etnias do Continente Africano ao tráfico negreiro. Perpassa pela formação dos quilombos que segundo Munanga (2009, p. 93) funcionavam como "uma cópia do quilombo afro-banto reconstruído pelos escravizados para se opor à estrutura escravocrata, pela implantação de outra estrutura política na qual se juntaram todos os oprimidos", a Abolição da Escravatura (1888) e as revoltas que adentram a proclamação da República (1889).

Durante as primeiras décadas do século XX surgiram os clubes compostos por afrodescendentes, de organizações consideradas "homens de cor", pois estes esforçavam-se para afastar qualquer ligação com uma matriz africana. No decorrer do tempo, os termos como negro e preto passaram a fazer parte do vocabulário dessas associações, urgindo assim a Frente Negra Brasileira, organização esta transformada num partido político no ano de 1931, mas extinta pela ditadura Vargas (GONÇALVES, 2011, p. 106). Em várias regiões do país foram realizados encontros de entidades negras a fim de tratar a questão racial, destacando-se o Teatro Experimental do Negro (TEN) (1944-1968) criado pelo intelectual Abdias Nascimento. Segundo Gomes (2017), o TEN também alfabetizava os seus primeiros membros, dentre eles, operários, domésticas, etc., e proporcionava a esses sujeitos uma formação crítica do atual contexto inserido. 
No ano de 1978 a ditadura militar prendeu, torturou e assassinou o feirante Robson Silveira da Luz, acusado de roubar frutas na feira. Ainda nesse ano, quatro crianças que jogavam vôlei foram discriminadas pelo Clube Regatas do Tietê, e o operário Nilton Lourenço foi morto pela Policia Militar, em São Paulo. Esses crimes tiveram uma reação imediata e por meio da articulação das organizações do Movimento Negro, fundaram uma organização nacional, o Movimento Unificado Contra a Discriminação ÉtnicoRacial (MUCDR) em 18 de junho 1978. Mais tarde, em dezembro de 1979, essa organização foi rebatizada como Movimento Negro Unificado (MNU) o qual contribuiu na formulação das demandas do Movimento negro à Assembleia Constituinte de 1988, por conseguinte deu origem à Constituição Cidadã.

Outro fator importante a ser destacado, ocorreu em meados da metade dos anos 90, após os estudos da biologia e da genética comprovarem que as raças humanas não existem no contexto biológico (MIRANDA, 2010), o termo raça foi ressignificado pelo Movimento Negro Unificado, desmistificando o mito da democracia racial, reintroduziu a ideia de raça a partir de uma origem africana cuja organização se deu a partir de um grupo identitário no combate ao preconceito e discriminação racial (GUIMARÃES, 2003). Outrora, o termo que servia para designar as raças/etnias inferiores, passa a ser adotado num contexto político e identitário e entendido como construção social forjada nas relações de poder por meio da colonização europeia.

Em seguida, o Movimento Negro, em 1995, realiza a "Marcha Nacional Zumbi dos Palmares contra o Racismo, pela Cidadania e a Vida", em Brasília, no dia 20 de novembro. A Marcha resulta na produção do documento "Programa para superação do racismo e da desigualdade étnico-racial", onde constavam algumas das demandas do Movimento, tais como que as ações afirmativas fossem implementadas na educação superior e no mercado de trabalho. Esse documento foi repassado para o presidente da época, Fernando Henrique Cardoso (FHC), na gestão deste foi criado o Grupo Interministerial do Trabalho para a Valorização da População Negra, no dia 27 de fevereiro de 1996. 
Ainda neste mesmo ano, foram elaborados os Parâmetros Curriculares Nacionais (PCNs) aprovados pelo Conselho Nacional de Educação (CNE), desenvolvidos entres os anos de 1995 e 1996, que norteiam um conjunto de conceitos, atitudes e valores serem desenvolvidos em sala de aula por estudantes, cujo tema transversal presente neste parâmetro é a Pluralidade Cultural, abordando a diversidade. Neste percurso histórico, no ano 2000, a luta do Movimento Negro se intensifica ainda mais. Em 2003, é criada a Secretaria de Políticas de Promoção da Igualdade Racial (Seppir) ${ }^{4}$ e a fundação da Associação Brasileira de Pesquisadores Negros (ABPN), órgão responsável pela realização do Congresso Brasileiro de Pesquisadores Negros (Copene). A ABPN surgiu com a proposta de agregar pesquisadoras (es) negras (os) ou não negras (os), que produzem saberes na área das relações raciais e outros temas do interesse da população negra ${ }^{5}$.

Durante o governo Lula, em 2004, por meio do Decreto $n^{\circ}$ 5.159, de 28 de julho de $2004^{6}$, foi criada pelo Ministério da Educação, a Secretaria de Educação Continuada, Alfabetização, Diversidade e Inclusão (Secadi). Esta secretaria surge por pressão dos movimentos sociais, em especial, o Movimento Negro, com a finalidade de garantir o direito especializado a Educação de Jovens e Adultos, Educação do Campo, Educação Escolar Indígena, Educação Escolar Quilombola, Educação para as Relações Étnico-raciais, Educação em direitos humanos. O Estado reconheceu as diferenças e diversidades entres esses grupos, comprometendo-se a garantir educação escolar que dialogasse com as suas realidades socioculturais. Entretanto, com o Decreto $n^{\circ}$ 9.465, de 2 de janeiro de 2019, extinguindo a Secadi, marcando assim um enorme retrocesso na área educacional, políticas e ações afirmativas.

Este breve histórico da trajetória do Movimento Negro, evidencia o protagonismo desse movimento social na luta por emancipação e asseguração de direitos para a população negra. Ao ressignificar o termo raça o Movimento Negro, assume ainda mais a

\footnotetext{
${ }^{4}$ Ver mais em: https://www.justica.gov.br/news/conheca-melhor-o-trabalho-da-seppir

${ }^{5}$ Ver mais em: https://www.abpn.org.br/

${ }^{6}$ Ver mais em: https://www2.camara.leg.br/legin/fed/decret/2004/decreto-5159-28-julho2004-533141-norma-pe.html
} 
posição de agente de transformação, de ator coletivo e de produtor de conhecimento. Dessa forma, ele reeduca a si mesmo, ao Estado e sociedade brasileira como um todo, produzindo novos saberes que também devem ser considerados legítimos, demonstrando que os direitos conquistados pelo Movimento Negro, nasce da luta de homens e mulheres negras e negros, agentes dotados de valores e saberes que construíram e constroem a história cultural do nosso país, e que se posicionam frente ao racismo, contribuindo na construção de políticas de equidade racial, visando o combate e a superação do racismo.

\section{O PENSAMENTO DECOLONIAL}

A colonização europeia deixou marcas profundas no mundo dito pós-moderno. Talvez, possamos dizer que, a causa de todas essas cicatrizes pode ser descrita através da invisibilização e subalternização dos indivíduos, saberes e conhecimentos integrantes dos povos latino-americanos. Por meio da invisibilização e subalternização dos saberes e conhecimentos desses povos, a escrita oficial da história da humanidade também foi obliterada, uma vez que houve uma negação do protagonismo desses povos na formação do que conhecemos hoje como modernidade. Com isso houve um enquadramento, senão um condicionamento do ser, do pensar e do saber. Através da negação do direito de autonomia à escrita da própria história esses povos estiveram sempre à margem do mundo, da ideia de progresso, da civilização, sob o argumento de que a racionalidade europeia é verdadeira, única e inquestionável foram impedidos de escrever a sua própria história, sendo esta tarefa digna apenas aos povos europeus que colonizaram as Américas, a Ásia e a África.

Entretanto, no século XXI, mais especificamente ao final dos anos de 1990, constitui-se o pensamento do Grupo Modernidade/Colonialidade (M/C), composto por intelectuais latinoamericanos de diferentes universidades das Américas, este grupo propõe uma nova epistemologia para se pensar e repensar a América Latina. A ideia de "Giro decolonial", termo cunhado por MaldonadoTorres em 2005, durante um encontro do grupo $M / C$, "que 
basicamente significa o movimento de resistência teórico e prático, político e epistemológico, à lógica da modernidade/colonialidade" (BALLESTRIN, 2013, p. 105), nos proporciona meios para fazer uma releitura histórica e refletir, do lugar social de subalternizados, sobre a colonialidade global que atravessa diferentes dimensões da vida pessoal e coletiva.

O grupo M/C confronta a história "oficial e universal" da humanidade e faz uma crítica a esta, uma vez que essa "oficialidade" e "universalidade" remete-se unicamente a história da Europa (tida como o centro do mundo), descrevendo o restante dos continentes como meros figurantes da história da civilização moderna/colonial. O grupo levanta questões fazendo referência a um pensamento crítico, no qual o ponto de partida são os subalternizados pela modernidade capitalista, assim é possível pensar a construção de um projeto epistemológico crítico e transdisciplinar que se contraponha às tendências acadêmicas eurocêntricas que são dominantes no conhecimento histórico e social. O mesmo é composto, em sua maior parte, por intelectuais da América Latina e possui uma composição diversificada e transdisciplinar. Um exemplo a esta diversificação são as áreas em que as figuras centrais deste grupo atuam: a linguista norte-americana radicada no Equador Catherine Walsh, o antropólogo colombiano Arturo Escobar, o sociólogo peruano Aníbal Quijano, o filósofo argentino Enrique Dussel, o semiólogo e teórico cultural argentino-norte-americano Walter Mignolo, o sociólogo porto-riquenho Ramón Grosfoguel, o filósofo porto-riquenho Nelson Maldonado Torres, entre outros (OLIVEIRA; CANDAU, 2010). Destacase ainda que este grupo mantém relações acadêmicas com o sociólogo norte-americano Imanuel Wallerstein.

A premissa central do grupo expressa-se por meio da afirmação de Mignolo (2005, p. 38) que enfatiza ser "difícil pensar que não pode haver modernidade sem colonialidade; a colonialidade é constitutiva da modernidade, e não derivativa.". Portanto, modernidade e colonialidade são faces distintas de uma mesma moeda. É por conta da colonialidade que o pensamento construído infere que apenas a Europa pode produzir as ciências como um caráter universal e oficial, no qual há objetividade. Graças à isto, todas as epistemologias do dito terceiro mundo foram negadas e 
invisibilizadas. Salienta-se que, apesar de colonialismo e colonialidade serem conceitos que mantem uma relação entre si, ainda assim são distintos. O colonialismo foi um sistema de dominação e exploração de um povo "soberano" em detrimento de outro povo considerado inferior, por isso o colonialismo em Quijano (2007):

[...] refere-se estritamente a uma estrutura de dominação/exploração onde o controlo da autoridade política, dos recursos de produção e do trabalho de uma população determinada domina outra de diferente identidade e cuja sedes centrais estão, além disso, localizadas noutra jurisdição territorial. Mas nem sempre, nem necessariamente, implica relações racistas de poder. O colonialismo é, obviamente, mais antigo, enquanto a Colonialidade tem vindo a provar, nos últimos 500 anos, ser mais profunda e duradoira que o colonialismo. Mas foi, sem dúvida, engendrada dentro daquele e, mais ainda, sem ele não poderia ser imposta na intersubjectividade do mundo tão enraizado e prolongado. (p. 72)

Este sistema de poder, marcou a América Latina por três séculos, tirando o excedente econômico do continente americano para manter e reproduzir o poderio da Europa. Assim, a dominação, a exploração e a opressão estão no cerne do colonialismo. Portanto, é inconcebível pensar que não há colonialismo sem dominação ou exploração (BALLESTRIN, 2013). Logo, este é mais do que uma mera imposição política ou militar. As independências políticas ocorridas nas colônias latino-americanas e nos países da África e da Ásia nos séculos XIX e XX, marcaram o fim do colonialismo - formal - como defendiam alguns intelectuais como, Homi Bhabha, Edward Said, Stuart Hall, entre outros autores considerados pós-coloniais. Entretanto dá-se início à um sistema neocolonial, uma vez que quem passa a dominar a América Latina são os Estados Unidos da América e não mais a Europa, como acontecia no antigo sistema colonial. Consequentemente, mesmo com o fim do colonialismo formal a colonialidade perpetua-se até os dias atuais, seja nas dimensões subjetivas, no imaginário ou no modelo epistemológico eurocêntrico 
que vigora nas instituições de ensino do mundo todo. Por isso, encaramos esta última como um condicionamento da racionalidade nas relações estabelecidas entre as pessoas e o mundo.

Quijano (2005) define o conceito de colonialidade do poder, caracterizada como uma estrutura de dominação que subalternizou os continentes da América Latina, a África e a Ásia. Este conceito define-se pela invasão do imaginário do outro, ou seja, a sua europeização ou mesmo ocidentalização, baseado na ideia eurocêntrica de que a Europa é superior. Uma vez que o colonizador arruína o imaginário do outro considerado não-civilizado, ele também causa a destruição, invisibilização e subalternização do imaginário deste, ao mesmo tempo em que reafirma o seu próprio imaginário.

Por conseguinte, pode-se assegurar que a colonialidade do poder foi o que construiu, moldou e condicionou a subjetividade dos povos e nações subalternizadas. Quijano (2000) assim como Munanga (2004) afirma que o conceito de raça é baseado numa ideia biológica errônea, abstrata e que não tem relação alguma com processos biológicos. Este conceito legitimado pelas ciências do século XIX-XX relegou aos grupos humanos não-europeus um lugar de inferioridade e subalternidade, justificando a divisão racial do trabalho, do salário, e das produções culturais, de saberes e conhecimentos.

Baseado no exposto, o autor também fala sobre a colonialidade do saber, encarada como a negação e deslegitimação de outras formas de conhecimentos situados fora do continente Europeu, posição essa que oblitera e sobrepõem-se ao legado intelectual e histórico de povos indígenas e africanos, confinando-os à posição de seres irracionais, bárbaros e primitivos, pois este pertencem a uma "outra raça", "diferente" daquela à qual pertencem os europeus. Evidencia-se portanto, toda a hegemonia do conhecimento centralizado na Europa, o que se constitui como um racismo epistêmico menos reconhecido em nível social, político e econômico. Grosfoguel (2007, p. 32) define o racismo epistemológico como aquele que: 
Opera privilegiando as políticas identitárias (identity politics) dos brancos ocidentais, ou seja, a tradição de pensamento e pensadores dos homens ocidentais (que quase nunca inclui as mulheres) é considerada como a única legítima para a produção de conhecimentos e como a única com capacidade de acesso à "universidade" e à "verdade". O racismo epistêmico considera os conhecimentos nãoocidentais como inferiores aos conhecimentos ocidentais.

Entende-se que, a epistemologia ocidental ocupa o lugar social de dominante, sendo assim, esta não admite nenhuma outra epistemologia como espaço de produção de conhecimento crítico e/ou científico (et. al, p. 35). Convencidos dessa hierarquia de conhecimento, ou então, num único locus produtor de conhecimento legítimo, o Norte considera a periferia (Sul) incapaz de produzir conhecimento e criar teorias, seguindo essa linha de raciocínio apenas o Norte é tido como o protagonista na produção epistêmica (BALLESTRIN, 2013). Entretanto, precisa-se conhecer outras ideias, ter contato com outros saberes e conhecimentos, sendo que estes foram e sempre serão diversos, apesar da invisibilidade a que foram submetidos.

Santos (2012) defende que para conhecer o mundo, a natureza, outros universos simbólicos, e holísticas sobre a vida, nós precisamos de outras experiências, apesar de que o conhecimento eurocêntrico foi construído para não valorizar essas outras experiências. Portanto, produzir conhecimentos, criar teorias, compartilhar saberes vindos do Sul do Globo é uma forma de resistir, de expor que a América Latina, a Ásia e a África fazem ciências também. Uma ciência legítima e cheia de valores. Por isso, este intelectual defende as epistemologias do Sul caracterizada como a diversidade epistemológica do mundo, uma vez que:

O mundo é epistemologicamente diverso e que essa diversidade, longe de ser algo negativo, representa um enorme enriquecimento das capacidades humanas para conferir inteligibilidade e intencionalidade às experiencias sociais. $A$ pluralidade epistemológica do mundo e, com ela, o 
reconhecimento de conhecimentos rivais dotados de critérios diferentes de validade tornam visíveis e credíveis espectros muito mais amplos de acções e de agente sociais. (SANTOS; MENESES, 2009, p. 12).

Portanto, as epistemologias do sul são um conjunto de intervenções epistemológicas que denunciam a supressão das diversas formas de saber e conhecer próprias dos povos e nações que foram submetidas ao processo de colonização (SANTOS; MENESES, 2009 , p. 13). Esta prática acarreta uma tentativa de fazer justiça cognitiva global, compartilhando outros conhecimentos dotados de saber científico e trazê-los para dentro dos espaços acadêmicos. Defende-se que a América Latina existe e resiste por si só, ela não é uma cópia da Europa, esta produz alternativas ao colonialismo/imperialismo do Norte. Além do grupo dominante ser aquele por quem a "verdade" é produzida, Mignolo (2005) afirma que o Estado legitimou as ciências humanas no ato de inventar "o outro", àquele que é pertencente à uma "outra raça", "inferior", "não civilizada" e "primitiva". O autor ainda afirma que essas ciências, como a história, por exemplo, criaram a noção de progresso. Nesse preambulo, Castro-Gómez (2005) afirma que a história e as áreas afins - nem todas -, ao estudarem os produtos culturais deixados pelas primeiras civilizações, permitiram - em algumas vezes - que fossem feitas comparações entre estas civilizações e a Europa, estas comparações, mais tarde, serviram como justificativa à pratica do colonialismo. Consequentemente, se o mundo europeu é o centro da história mundial e ocupa o topo da escala de hierarquia, este é o único padrão possível de comparação. Dessa forma, "a Europa demarcou o caminho civilizatório pelo qual deverão transitar todas as nações do planeta" (et.al, p. 34).

Mignolo (2003) explicita como os espanhóis classificavam a inteligência dos povos, primeiro com base na escrita alfabética e mais tarde, nos séculos XVIII e XIX, baseados na história, logo a colonialidade do poder deu base para:

O eurocentrismo tornar-se, portanto, uma metáfora para descrever a colonialidade do poder, na perspectiva da subalternidade. Da perspectiva epistemológica, o saber e as histórias locais 
europeias foram vistos como projetos globais, desde o sonho de um Orbis universalis christianus até a crença de Hegel em uma história universal, narrada de uma perspectiva que situa a Europa como ponto de referência e de chegada. (p. 41).

O autor afirma que a história "universal" contada por Friedrich Hegel, negou - ainda - aos personagens a posição de narradores, sendo confinados a função de figurantes. Segundo Mignolo, a expansão ocidental ocorrida após o século XVI, além de econômica e religiosa, foi também a expansão de um padrão hegemônico do conhecimento, no qual a Europa aparecia como detentora de todo o saber científico, dessa forma, dava-se início à colonialidade do saber. Desta forma, retoma-se o conceito de colonialidade do saber para destacá-la, antes de tudo, como uma violência epistêmica, uma vez que esta, por meio de uma geopolítica linguística determinou um monopólio linguístico, desprezando as línguas nativas dos povos indígenas, africanos e asiáticos (MIGNOLO, 2005).

É unânime entre os teóricos citados até aqui que é por meio do conceito da colonialidade do ser que os outros conceitos abordados anteriormente se reafirmam, visto que, a colonialidade do ser consiste na inferiorização, invisibilização e desumanização do "outro". Fanon (2008) descreve esta como o "tratamento da nãoexistência". Fernanda Bragato (2014) estabelece uma relação entre razão, racionalidade e humanidade, para descrever este conceito. Segundo a autora, os "mais humanos" são aqueles que exercem uma racionalidade formal (Estado nacional) e os "menos humanos", são aqueles que não se encaixam nesse molde. Coloca-se os indígenas como bárbaros e não-civilizados e, os povos negros como nãoexistentes.

Esta concepção resulta nas construções históricas que confinam os colonizados num lugar social de inferioridade, sendo esta concepção subjacente dos discursos eurocêntricos, no qual acredita-se haver uma periferia e um lócus de enunciação legitimo e central (BRAGATO, 2014). Ademais, segundo Oliveira (2018, p. 51), encara-se a colonialidade do ser "como uma negação de um estatuto humano para africanos e indígenas, por exemplo, na história da modernidade colonial". 
Partindo dessas considerações teóricas elencadas até aqui, ressalta-se que o Grupo $\mathrm{M} / \mathrm{C}$ não tem o objetivo de desvalorizar a produção epistêmica da Europa, mas apontar a existência de outras epistemes produzidas fora do eixo do Norte Global, bem como, colocar essas diversas epistemologias para dialogar, sendo este um mecanismo para difusão de formas de conhecimentos entre a academia, os movimentos sociais (destaca-se o MN), as camadas populares, enfim, um diálogo entre o Norte e o Sul Global.

\section{A PRÁtICA PEDAGÓgICA DECOLONIZAdORA PARA O ANTIRRACISMO NO CHÃO DA ESCOLA}

Propor uma prática pedagógica decolonizadora é, antes de tudo, um ato de resistência e o início da construção de uma sociedade democrática, de uma sociedade "outra". A pedagogia decolonial constitui-se, também, através de um projeto político emancipatório, sendo assim, também se configura como prática de resistência que decolonializa o poder, o ser e o saber.

As pedagogias pensadas por Freire, englobam ações sociais como a humanização, a dialogicidade, a conscientização individual e coletiva, a problematização da realidade que nos cerca e a emancipação radical do nosso ser. Para este teórico a prática pedagógica deve partir da realidade e modos de viver de quem se pretende educar, seja formal ou informalmente. Suas proposições dialogam com a linha de pensamento da linguista Catherine Walsh (2002, 2005, 2006, 2007), sendo que as experiencias vividas pelos povos subalternizados ${ }^{7}$ devem contribuir como o ponto de partida para a reflexão das cidadãs e cidadãos que queremos formar nas escolas do Brasil inteiro, pois "sem os dados empíricos a reflexão pedagógica torna-se vazia, sem referenciais teóricos, sua atuação torna-se cega" (MÜHL, 2011, p. 12-13). E, como essas reflexões

\footnotetext{
${ }^{7}$ Paulo Freire, em todas as suas obras teóricas utiliza o termo "oprimido", para referir-se às camadas populares vítimas das violências do estado, enquanto a teórica Catherine Wash faz uso do termo "subalternizado", assim como os outros integrantes do Grupo Modernidade/Colonialidade.
} 
espelharão nas práticas pedagógicas adotadas por professoras e professores nas escolas brasileiras.

As práticas pedagógicas refletem as relações do mundo que há fora dos muros das instituições de ensino. Para isto, adotamos o conceito de Freire (1987, p. 121) que ao falar da prática pedagógica e sua relação com a práxis educativa, estabelece que se "os homens são seres do quefazer é exatamente porque seu fazer é ação e reflexão. É práxis. É transformação do mundo". Pensando nisso, é necessário romper com a ideia de que a teoria e a prática devem estar separadas, pois para uma transformação do mundo, é urgente que se reconheça que o saber não está somente na teoria, mas na ação também, nas práticas diárias do cotidiano.

Portanto, se a práxis é reflexão e ação, é impossível conceber que sem ela seria possível superar a relações de poder impostas pelo grupo hegemônico (FREIRE, 1987, p. 38), assim ressalta-se que "o seu quefazer, ação e reflexão, não pode dar-se sem a ação e a reflexão dos outros, se seu compromisso é o da liberdade" (p. 122).

Assim, falamos sobre a posição que educadores ocupam e assumem nas escolas do país. Agir como mediadora e mediador exige práxis. Tratar sobre as relações étnico-raciais exige práxis. Ser decolonial exige práxis. Atuar como pedagoga e pedagogo decolonial exige práxis. Assumir a posição de antirracista nas instituições de ensino exige práxis. $E$, práxis também é resistência diária. Ou seja, é indispensável que estejamos sempre em processo de ação e reflexão.

O filósofo e pedagogo brasileiro, Dermeval Saviani explicita como a prática pedagógica deve se manter em constante movimento, e que essa movimentação tenha em si o beneficio da dúvida, da reflexão, do questionamento, pois Saviani (2005) considera que:

Quando entendemos que a prática será tanto mais coerente e consistente, será tanto mais qualitativa, será tanto mais desenvolvida quanto mais consistente for a teoria que a embasa, e que uma prática será transformada à medida que exista uma elaboração teórica que justifique a necessidade da sua transformação e que proponha as formas de transformação, estamos pensando a prática a partir 
da teoria. Mas é preciso também fazer o movimento inverso, ou seja, pensar a teoria a partir da prática, porque se a prática é o fundamento da teoria, seu critério de verdade e sua finalidade, isto significa que o desenvolvimento da teoria depende da prática (p.107).

Por meio da ação-reflexão-ação é possível repensar a prática pedagógica e, o impacto que esta tem na construção da identidade étnico-racial da população afro-brasileira. Como já exposto, em um dos capítulos anteriores, a Constituição de 1988 - nos artigos 215 e 242 - reconheceu a pluralidade étnica do nosso país e a influência africana na cultura brasileira, diante disso, nos anos subsequentes o MN protagonizou lutas em prol da conquista de reinvindicações históricas. Estas reinvindicações se tornaram mais frequentes a partir dos anos 80 e 90, pois segundo Oliveira e Candau (2010, p. 29) "o conceito de afrodescendência ganha força enquanto fator de mobilização social e categoria histórica definidora de um pertencimento étnico", soma-se à isso que categorias como cultura, identidade e etnia ganham destaque nas discussões sobre educação, em geral.

A elaboração dos PCNs - após as reformas educacionais dos anos 90 - designa mais uma das práticas antirracistas efetuada graças a luta do MN que fizeram pressão no Governo, com base nas orientações desde documento onde educadores teriam meios de como aplicar uma prática pedagógica crítica acerca das relações raciais no Brasil, sendo um dos objetivos da área curricular de História, construir a noção de identidade, por meio da abordagem de identidades individuais, coletivas e sociais de acordo com Silva (1995):

Identidade é um conceito que abrange duas dimensões: a pessoal e a social... A identidade social surge do processo de identificação do indivíduo com aqueles considerados importantes em sua socialização. Logo a identidade social se interrelaciona com a identidade pessoal; sendo assim, não existe a possibilidade de uma identidade pessoal desvinculada da identidade social. (p. 26). 
A Lei 10.639, de 9 de janeiro de 2003, é lida como uma ação antirracista do $\mathrm{MN}$, bem como de diversas educadoras e educadores preocupadas (os) com as assimetrias étnico-raciais existentes no país. O empenho do Movimento e desses educadores configura-se como uma das formas da luta antirracista, leva-se em consideração que a Lei não é cumprida em sua totalidade, pois nas escolas ainda apresentam práticas isoladas acerca da abordagem das relações raciais. Nessa direção, Miguel Arroyo (2012, p. 173) expõe que:

\begin{abstract}
Para os coletivos em movimento da diversidade e até as políticas do Estado são respostas tímidas as suas pressões por afirmar-se visíveis, presentes. Colocar-se na agenda política ou pedagógica, e até na pauta das análises de políticas o reconhecimento da diversidade, das diferenças vem apresentando uma conquista das lutas dos diferentes, e suas pressões não param por aí: pressionam por que sejam reconhecidos seus processos, suas lutas por autorreconhecimentos. Por reconhecimento das Outras Pedagogias, autopedagogias coletivas em que produzem suas autoidentidades positivas.
\end{abstract}

Como exposto, os movimentos sociais são ferramentas importantes diante das necessidades dos grupos sociais e, estes lutam pelo autorreconhecimento de seu grupo, de forma que o Estado seja mais efetivo em suas políticas para que, de fato, as transformações sejam efetuadas.

Os estudos para uma para uma educação antirracista não cessam aí, Ramón Grosfoguel, os estudos étnicos nos Estados Unidos, geraram uma insurgência epistêmica ocorrida após várias greves e ocupações estudantis nas universidades, conduziram à criação de estudos afro-americanos possibilitando a abertura de espaços para educadores pertencentes a grupos etno-raciais subalternizados e discriminados, pois para Grosfoguel (2007, p. 32):

Se a epistemologia eurocêntrica se caracteriza não apenas por privilegiar um padrão de pensamento ocidental mas também por estudar o "outro" como objeto e não como sujeito que produz conhecimentos (encobrindo, ao mesmo tempo, a 
geopolítica e a corpo-política do conhecimento, a partir das quais pensam os pensadores e intelectuais acadêmicos brancos), a entrada de professores "de cor", com os programas de ação afirmativa e a criação de programas de estudos étnicos dirigidos a estudar os problemas que confrontam as minorias discriminadas, constituiu uma mudança importante na produção de conhecimentos acadêmicos.

Podemos perceber em Catherine Walsh que a interculturalidade crítica nos leva a um projeto político antirracista, sendo que para uma educação antirracista precisamos estar "envolvidos com processos que derivam da particularidade da dimensão do ser que é acional, subjetiva e situada [...] e que encontra sua base nas experiências entrelaçadas e vividas da escravidão e do colonialismo" (WALSH, 2014, p. 36). Durante as primeiras décadas do século $\mathrm{XXI}$, presenciamos embates históricos sobre o racismo à brasileira (TELLES, 2003) e, urgências de um projeto educacional sociopolítico inclusivo e emancipador, para isto, Munanga (2001, p. 8):

o preconceito incutido na cabeça do professor e sua incapacidade em lidar profissionalmente com a diversidade, somando-se ao conteúdo preconceituoso dos livros e materiais didáticos e às relações preconceituosas entre os alunos de diferentes ascendências étnico-raciais, sociais e outras, desestimulam o aluno negro e prejudicam seu aprendizado.

A construção de um projeto social voltado à prática pedagógica decolonizadora para uma educação antirracista é possível. O giro epistêmico (MALDONADO-TORRES, 2007), sendo um movimento de resistência teórico, político e epistemológico, frente à lógica da modernidade/colonialidade permite a superação dos padrões hegemônicos vigentes, pois através deste conceito evidencia-se espaços epistemológicos, antes invisibilizados pela lógica que opera na modernidade/colonialidade. 
Para tanto, a proposta de uma pedagogia decolonial e da interculturalidade crítica proposta por Catherine Walsh, demanda "a superação tanto de padrões epistemológicos hegemônicos no seio da intelectualidade brasileira quanto a afirmação de novos espaços de enunciação epistêmica nos movimentos sociais" (OLIVEIRA; CANDAU, 2010, p. 36). Um projeto social direcionado à prática pedagógica decolonizadora para uma educação antirracista, é uma forma de resistência frente à colonialidade do poder, do ser e do saber. Baseando-se no pensamento de Walsh (2006) é também um "projeto de existência e de vida".

Portanto, precisamos reconhecer o racismo em nós, assim a comunidade como um todo e, por conseguinte, aos educadores que também fazem parte dessa comunidade reeducarão a si mesmas na finalidade de superar o racismo e construir relações étnico-raciais "outras".

\section{CONSIDERAÇÕES FINAIS}

A luta do Movimento Negro por educação, saúde e reconhecimento histórico, social e político é antiga, entretanto discutir identidade étnico-racial quando se vive no país da "democracia racial" é difícil, mesmo a partir da lei 10.639/03 que instituiu a obrigatoriedade do Ensino de História e Cultura AfroBrasileira e Africana, lei que permitiu que as escolas da educação básica portassem um documento legal, que garante o direito de negras e negros brasileiros reconhecer-se na história do nosso país.

A superação das marcas deixadas por mais de 500 anos de escravidão, necessita de uma nova posição, crítica, antirracista, que não só denuncie o racismo, mas que o combata. Assim, podemos não só repensar, mas reconstruir e reestruturar as relações étnico-raciais e sociais no Brasil. Para tal, defende-se novamente que um dos primeiros passos a ser tomado é a superação do etnocentrismo europeu, crença de que o continente europeu é superior a todos os outros continentes e suas culturas, pois através da colonização da África, da Ásia e das Américas fomos condicionados a pensar que é na Europa que reside o poder, o conhecimento, o saber e a cultura. 
Precisa-se desfazer esse imaginário que reproduz relações de poder que nos hierarquizam como superiores e inferiorizados, civilizados e não-civilizados. Não podemos reduzir toda essa problemática a meras palavras, desprezando a experiência que a comunidade negra e afrodescendente tem no lugar de subalternidade e invisibilidade, este lugar que foi relegado a população negra por séculos de opressão e escravização.

Daí a necessidade de se estabelecer um constante diálogo com o Movimento Negro de todas as regiões do país e assim vencer as desvantagens e disparidades sociais, políticas, econômicas e raciais na qual o povo negro brasileiro foi confinado. Precisa-se de uma nova pedagogia, uma pedagogia decolonial como projeto político de combate ao racismo e as discriminações, que exalte o Norte e o Nordeste do Brasil, a Amazônia, a África como berço da humanidade e a América Latina como produtora de conhecimento válido e legítimo.

Reconhecer e valorizar a nossa cultura são um dos meios que dão suporte às colaboradoras e colaboradores desta pesquisa para assumirem as suas identidades étnico-raciais. Logo, tratar deste assunto, incluí-lo e executá-lo, de fato, no currículo escolar pode ser encarado como o início de um processo de empoderamento do grupo social estigmatizado, a saber a população negra, pois somente por meio de uma coletividade empoderada é possível realizar mudanças estruturais no padrão vigente da sociedade. Toda a história e cultura de um povo e de descendentes deste deve integrar todo o processo de ensino-aprendizagem no decorrer do ano letivo.

Assim, precisamos romper com a colonialidade do ser (WALSH, 2005), do poder (MIGNOLO, 2003) e do saber (MIGNOLO, 2005), através do "giro decolonial", caracterizado como um movimento de resistência frente a lógica da modernidade/colonialidade (MALDONADO-TORRES, 2005) podemos fazer uma releitura histórica e refletir, do lugar social de subalternizados, sobre a colonialidade global que atravessa e afeta diferentes dimensões da vida pessoal e coletiva.

Assim, a pedagogia decolonial e a interculturalidade crítica proposta por Catherine Walsh, demandam "a superação tanto de padrões epistemológicos hegemônicos no seio da intelectualidade 
brasileira quanto a afirmação de novos espaços de enunciação epistêmica nos movimentos sociais" (OLIVEIRA; CANDAU, 2010, p. 36), onde um projeto social direcionado à prática pedagógica decolonizadora para uma educação antirracista, é uma forma de resistência frente à colonialidade do poder, do ser e do saber. Baseando-se no pensamento de Walsh (2006) é também um "projeto de existência e de vida".

\section{REFERÊNCIAS}

ARROYO, Miguel G. Outros sujeitos, outras pedagogias.

Petrópolis, RJ: Vozes: 2012.

BALLESTRIN, Luciana. América latina e o giro decolonial. Revista Brasileira de Ciência Política, Brasília, n. 11, p. 89-117, maio/ago. 2013. Disponível em:

http://www.scielo.br/scielo.php?script=sci_arttext\&pid =S010333522013000200004. Acesso em: 20 nov. 2019.

BARDIN, Laurence. Análise de conteúdo. Tradução de Luís Antero Reta e Augusto Pinheiro. Lisboa: Edições 70, 2006. (Obra original publicada em 1977)

BARDIN, Laurence. Análise de conteúdo. São Paulo: Edições 70, 2011.

BRAGATO, Fernanda Frizzo. A lógica da colonialidade e a negação de direitos aos seres (menos) humanos. In: Conversações Interculturais no Sul Global, 2014. São Leopoldo/RS: Unisinos. 1 video (24min). Disponível em:

https://www.youtube.com/watch?v=I0yueBhnOdA. Acesso em: 01 out. 2019.

BRASIL. Parâmetros Curriculares Nacionais (PCNs). Ensino. Fundamental. Terceiro e quarto ciclos. Brasília: MEC/SEF, 1998.

CASTRO-GÓMEZ, Santiago. Ciencias sociales, violência epistémica y el problema de la invención del outro. In: LANDER, Edgardo (Org).

La colonialidad del saber: eurocentrismo y ciências sociales. Perspectivas Latinoamericanas. Buenos Aires: Clacso, 2005. 
FANON, Frantz. Pele negra, máscaras brancas. Bahia: Editora Edufba, 2008.

FREIRE, Paulo. Educação como prática da liberdade. Rio de Janeiro: Paz e Terra. 2009.

FREIRE, Paulo. Pedagogia do Oprimido. 17. ed. Rio de Janeiro: Paz e Terra, 1987.

FREYRE, Gilberto. Casa Grande e Senzala. Rio de Janeiro, Schmidt Editor, 1933.

GOMES, Nilma Lino. 0 movimento negro educador: saberes construídos nas lutas por emancipação. Petrópolis, RJ: Vozes, 2017.

GONÇALVES, Luiz Alberto Oliveira. Pensar a educação, pensar o racismo no Brasil. In: FONSECA, Marcus Vinícius; SILVA, Carolina Mostaro Neves da, FERNANDES, Alexsandra Borges (Orgs.).

Relações étnico-raciais e educação no Brasil. Belo Horizonte: Mazza Edições, 2011. p. 93-144. ISBN 978-85-7160-545-9.

GROSFOGUEL, Ramon. Dilemas dos estudos étnicos norteamericanos: multiculturalismo identitário, colonização disciplinar e epistemologias descoloniais. Ciências e cultura. São Paulo, v. 59, n. 2, p. 32-35, 2007.

GROSFOGUEL, Ramon. Para descolonizar os estudos de economia política e os estudos pós-coloniais: transmodernidade, pensamento de fronteira e colonialidade global. In: SANTOS, Boaventura de Souza; MENEZES, Maria Paula (Org.). Epistemologias do Sul. Coimbra, Portugal: Cortez, 2010.

GUIMARÃES, Antônio Sérgio Alfredo. Como trabalhar com "raça" em sociologia. Educ Pesq., v. 29, n. 1, p. 93-107, jan./jun. 2003.

GUIMARÃES, Antônio Sérgio Alfredo. Racismo e anti-racismo no Brasil. Rio de Janeiro: Ed. 34. 1999. Disponível em: http://www.justificando.com/2019/01/17/extincao-secadi-campoeducacao-conjuntura-atual/ . Acesso: 11 set. 2019.

MALDONADO-TORRES, Nelson. Sobre la colonialidad del ser: contribuciones al desarrollo de un concepto. In: CASTRO-GÓMEZ, S.; GROSFOGUEL, R. (Orgs.). El giro decolonial. Reflexiones para una 
diversidad epistémica más allá del capitalismo global. Bogotá: Universidad Javeriana-Instituto Pensar, Universidad Central-IESCO, Siglo del Hombre Editores, 2007. p. 127-167. Disponível em: http://www.unsa.edu.ar/histocat/hamoderna/grosfoguelcastrogome z.pdf. Acesso em: 21 nov. 2019.

MIGNOLO, Walter. Histórias locais - projetos globais:

colonialidade, saberes subalternos e pensamento liminar. Belo Horizonte: Ed. UFMG, 2003.

MIGNOLO, Walter. A colonialidade de cabo a rabo: o hemisfério ocidental no horizonte conceitual da modernidade. In: LANDER, Edgardo. (Org). A colonialidade do saber: eurocentrismo e ciências sociais. Perspectivas latino-americanas. Buenos Aires: CLACSO, 2005, p. 34-54.

MIRANDA, Monique. Classificação de raça, cor e etnia: conceitos, terminologia e métodos utilizados nas ciências da saúde no Brasil, no período de 2000 à 2009. 137 f. Dissertação (Mestrado em Ciências na área de Saúde Pública) - Escola Nacional de Saúde Pública Sergio Arouca, Rio de Janeiro, 2010.

MÜHL, Eldon Henrique. Práxis Pedagógica: Ação dialógica comunicativa e emancipação. In: MÜHL, Eldon Henrique; SARTORI, Jerônimo; ESQUINSANI, Valcir Antonio (Org.). Diálogo, ação comunicativa e práxis pedagógica. Passo Fundo: Ed. Universidade de Passo Fundo, 2011, p. 11-24.

MUNANGA, Kabengele. Apresentação. In: MUNANGA, K (org.).

Superando o racismo na escola. Brasília: MEC, 2001.

MUNANGA, Kabengele. Origens africanas do Brasil

contemporâneo: histórias, línguas, culturas e civilizações. São Paulo: Global, 2009.

MUNANGA, Kabengele. As ambiguidades do racismo à brasileira. In: KON, Noemi Moritz; ABUD, Cristiane Curi; SILVA, Maria Lúcia (Orgs.). 0 racismo e o negro no Brasil: questões para a psicanálise. I. ed. São Paulo: Perspectiva, 2017. p. 33-55. 309 p. 
MUNANGA, Kabengele. Uma abordagem conceitual das noções de raça, racismo, identidade e etnia. In: Programa de educação sobre o negro na sociedade brasileira [S.I,: s.n.], 2004.

OLIVEIRA, Luiz Fernandes de. Educação e militância decolonial. Rio de Janeiro: Editora Selo Novo, 2018, 152p.

OLIVEIRA, Luiz Fernandes de; CANDAU, Vera Maria Ferrão.

Pedagogia decolonial e educação antirracista e intercultural no

Brasil. Educ. rev. [online]. 2010, v. 26, n.1, p.15-40. ISSN 0102-4698.

Disponível em:

http://www.scielo.br/scielo.php?pid=S010246982010000100002\&scr ipt=sci_abstract\&tlng=pt. Acesso em: 03 nov. 2019.

QUIJANO, Aníbal. Colonialidaddel poder y clasificación social. In: CASTRO-GÓMEZ, S.; GROSFOGUEL, Ramon. (Orgs.). El giro

decolonial: reflexiones para una diversidad epistémica más allá del capitalismo global. Bogotá: siglo del Hombre Editores. Universidad Central, Instituto de Estudios Sociales Contemporáneos y Pontificia Universidad Javeriana. 2007.

QUIJANO, Aníbal. Don Quijote y los molinos de viento en América Latina. Revista Electrónica de Estudios Latinoamericanos, Buenos Aires, v. 4, n. 14, jan./mar. 2005.

QUIJANO, Aníbal. Modernidad y democracia: intereses y conflictos. Anuario Mariateguiano, Lima, v. 12, n. 12, 2000.

SANTOS, Boaventura de Sousa. Public Sphere and Epistemologies of the South. Africa Development, v. 37, n. 1, p. 43-67, 2012.

SANTOS, Boaventura de Sousa; MENESES, Maria Paula.

Epistemologias do Sul. Revista Lusófona de Educação, v.13, 2009.

SAVIANI, Dermeval. Pedagogia Histórico-Crítica: primeiras aproximações. 9. ed. Campinas: Autores Associados, 2005.

SILVA, Consuelo Dores. Negro qual é o seu nome? Belo Horizonte: MAZZA, 1995.

TELLES, E. Racismo à brasileira: uma nova perspectiva sociológica. Rio de Janeiro: Relume-Dumará: Fundação Ford, 2003. 347 p. 
WALSH, Catherine. Pensamiento crítico y matriz (de)colonial: reflexiones latinoamericanas. Otros. Quito: Universidad Andina Simón Bolívar / Abya-Yala , 2005 , 302 p. , formato: $15 \times 21 \mathrm{~cm}$, ISBN: 9978-19-103-8

WALSH, Catherine. Indisciplinar las ciencias sociales. Geopolíticas del conocimiento y colonialidad del poder: perspectivas desde lo andino, Otros, Quito: Universidad Andina Simón Bolívar / Abya-Yala, 2002. $248 \mathrm{p}$.

WALSH, C. Interculturalidad y colonialidad del poder. Un pensamiento y posicionamiento 'otro' desde la diferencia colonial". In: WALSH, C.; LINERA, A. G.; MIGNOLO, W. Interculturalidad, descolonización del estado y del conocimiento. Buenos Aires: Del Signo, 2006. p. 21-70.

WALSH, Catherine. Interculturalidad y colonialidad del poder: un pensamiento y posicionamiento otro desde la diferencia colonial. In: LINEA, A.; MIGNOLO. W.; WALSH, Catherine. Interculturalidad, descolonización del Estado y del conocimiento. Buenos Aires: Ediciones del signo, 2014. p. 17-51.

WALSH, Catherine. Interculturalidad y colonialidad del poder: Un pensamiento y posicionamiento "otro" desde la diferencia colonial p. 47-62. In: CASTRO-GÓMEZ, Santiago; GROSFOGUEL, Ramón. EI giro decolonial: reflexiones para una diversidad epistémica más allá del capitalismo global. Bogotá: Siglo del Hombre Editores; Universidad Central, Instituto de Estudios Sociales Contemporáneos y Pontificia Universidad Javeriana, Instituto Pensar, 2007. 308 p.

Submetido em: Junho/ 2020.

Aceito em: Setembro/ 2020. 